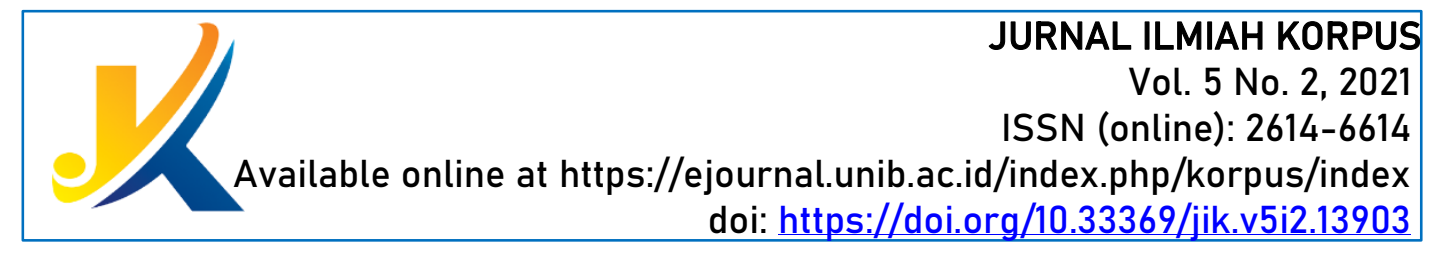

\title{
PEMANFAATAN MEDIA PEMBELAJARAN GOOGLE SITES DALAM PEMBELAJARAN BAHASA INDONESIA JARAK JAUH SISWA KELAS VII SMP ISLAM ASY-SYUHADA KOTA BOGOR
}

\author{
Rosiyana \\ Universitas Islam Negeri Syarif Hidayatullah Jakarta \\ Korespondensi: rosi.yana18@mhs.uinjkt.ac.id
}

\begin{abstract}
Abstrack
Salah satu teknologi yang dilakukan dalam proses pembelajaran jarak jauh adalah teknologi internet. Salah satunya google sites, bisa dimanfaatkan oleh siswa dalam kondisi pandemi Covid-19 ini, yang tentu saja dalam hal ini sangat dibutuhkan oleh tenaga pendidik dalam melakukan pembelajaran. Tujuan artikel ini untuk mengetahui manfaat google sites dalam pembelajaran jarak jauh dalam pembelajaran Bahasa Indonesia dan mengembangkan kreativitas siswa dalam menggunakan google sites dalam pembelajaran jarak jauh. Dalam proses pembelajaran google sites akan baik jika digunakan untuk poses pembelajaran jarak jauh. Pembelajaran menggunkan google sites memberikan manafaat bagi peserta didik dan guru. Manfaat google sites yaitu sebagai berikut (1) google sites dapat membuat siswa lebih menarik dan menyenangkan (2) google sites dapat memberikan materi pembelajaran yang bisa diunduh sehingga siswa dapat belajar dari materi dimana pun dan kapan pun (3) goole sites dapat memberikan materi yang dari awal sampai akhir pertemuan, siswa dapat membaca kembali materi yang diberikan oleh guru karena materi tidak otomatis hilang (4) siswa dapat menguplosd tugas yang sudah diberikan tempat tugasnya tersendiri (5) google sites dapat memberikan pengumuman tersendiri mengenai tugas, atau informasi yang lain (6) menambahkan video dari Youtube secara langsung, dan lain-lain. Hasil penelitian bahwa siswa Kelas VII SMP Islam Asy-Syuhada dalam pembelajaran bahasa Indonesia jarak jauh menggunkan media google sites dapat membawa siswa lebih efektif dan menarik sehingga akan mengembangkan kemampuan siswa dalam proses pembelajaran.
\end{abstract}

Kata Kunci: Manfaat Google Sites, Pembelajaran Jarak Jauh, Kreatif Siswa.

Abstract

One of the technologies used in the distance learning process is internet technology. One of them is google sites, which can be used by students in the conditions of the Covid-19 pandemic, which of course in this case is very much needed by educators in conducting learning. The purpose of this article is to find out the benefits of google sites in distance learning in Indonesian language learning and to develop students' creativity in using google sites in distance learning. In the learning process google sites will be good if used for distance learning poses. Learning using google sites provides benefits for students and teachers. The benefits of google sites are as follows (1) google sites can make students more interesting and fun (2) google sites can provide learning materials that can be downloaded so that students can learn from material anywhere and anytime (3) goole sites can provide material that is from the beginning to the end of the meeting, students can read back the material provided by the teacher because the material is not automatically lost (4) students can upload assignments that have been assigned their own assignment (5) google sites can provide 
separate announcements about assignments, or other information ( 6) add videos from Youtube directly, and others. The results showed that the seventh grade students of SMP Islam Asy-Syuhada in Indonesian language learning using google sites media could bring students more effectively and attractively so that they would develop students' abilities in the learning process.

Keywords: Benefits of Google Sites, Distance Learning, Student Creative.

\section{PENDAHULUAN}

Dalam kondisi pandemi Covid-19 ini pembelajaran dilakukan secara jarak jauh. Dalam proses pembelajaran jarak jauh siswa harus menggunakan teknologi sebagai alat media pembelajaran yaitu menggunakan internet. Dalam bidang pendidikan, internet dapat memberikan tenaga pendidik untuk memiliki akses yang mudah atas berbagai macam informasi di dalam internet dalam pembelajaran jarak jauh. Internet memudahkan siswa dalam proses mencari informasinya, misalnya mencari tugas yang diinginkan, mencari berita, artikel, buku, dan lain-lain.

Pembelajaran merupakan berasal dari kata "instruction" yang dalam bahasa Yunani disebut instructus atau "intruere" yang berarti menyampaikan pikiran (Bambang: 2008 :265). Kata pembelajaran mempunyai makna pro-aktif dalam melaksanakan suatu kegiatan belajar, sebab di dalam suatu kegiatan belajar bukan hanya pendidik tetapi di dalam suatu kegiatan belajar ada peserta didik yang merupakan subjek yang aktif dalam proses pembelajaran (Hamzah: 2011:70).

Pembelajaran daring adalah pembelajaran yang dilakukan siswa dan guru dengan jarak jauh . pembelajaran jarak jauh biasanya dilakukan menggunakan teknologi internet. Dalam siswa kelasVII SMP Islam Asy-syuhada dalam proses pembelajaran menggunakan jarak jauh yaitu menggunakan google sites. Pembelajaran jarak jauh menggunakan internet contohnya internet, radio, handphone dan lain-lain.

Salah satu teknologi yang mempengaruhi pembelajaran dimasa pandemi Covid-19 ini adalah teknologi internet. Teknologi Internet sangat dibutuhkan oleh siswa saat melakukan pembelajaran, dengan adanya intenet siswa bisa mencari atau memanfaatkan internet tersebut dengan baik, internet juga tidak dibatasi pada waktu dan jarak, bisa dilakukan kapan saja dalam kegiatan pembelajaran. Ditambah lagi pada saat pandemi seperti ini pembelajaran dilakukan melalui online.

Menurut (Nunu: 2012: 24) menyebutkan bahwa "media" berasal dari bahasa Latin "medium" yang berarti "perantara" atau "pengantar". Menurut (Rusman: 2013: 169) Media adalah pengantar pesan dari pengirim ke penerima pesan, dengan demikian media merupakan wahana penyalur informasi belajar atau penyalur pesan.

Menurut (Hamzah: 2011: 122) media pembelajaran adalah segala bentuk alat komunikasi yang dapat digunakan untuk menyampaikan informasi dari sumber ke peserta didik secara terencana sehingga tercipta lingkungan belajar yang kondusif dimana penerimanya dapat melakukan proses belajar secara efisien dan efektif. Menurut (Rubhan Masykur: 2017:179) Media pembelajaran digunakan sebagai sarana pembelajaran di sekolah bertujuan untuk dapat meningkatkan mutu pendidikan. 
Penggunaan internet banyak digunakan peserta didik dalam proses pembelajaran jarak jauh dalam kondisi pandemic Covid-19. Internet sangat penting dalam pembelajaran jarak jauh, karena internet dapat memberikan informasi , atau mengirim tugas dalam proses pembelajaran oleh karena itu, media yang digunakan siswa Kelas VII SMP Islam AsySyuhada dalam pembelajaran bahasa Indonesia jarak jauh menggunakan google sites.

Google sites merupakan cara yang praktis dalam pembelajaran karena memberikan informasi pembelajaran dengan cepat dan bisa diakses dimana pun dan kapan pun. Google sites dapat memberikan efektif dalam proses pembelajaran jarak jauh dalam kondisii pandemi Covid-19, karena memberikan kemudahan dalam proses pembelajaran. Pembelajaran menggunkan google sites memberikan manafaat bagi peserta didik dan guru. Manfaat google sites yaitu sebagai berikut (1) google sites dapat membuat siswa lebih menarik dan menyenangkan (2) google sites dapat memberikan materi pembelajaran yang bisa diunduh sehingga siswa dapat belajar dari materi dimana pun dan kapan pun (3) goole sites dapat memberikan materi yang dari awal sampai akhir pertemuan, siswa dapat membaca kembali materi yang diberikan oleh guru karena materi tidak otomatis hilang (4) siswa dapat mengaploud tugas yang sudah diberikan tempat tugasnya tersendiri (5) google sites dapat memberikan pengumuman tersendiri mengenai tugas, atau informasi yang lain. Oleh karena itu pada artikel kali ini akan membahas mengenai bagaimana pemanfaatan google sites dalam pembelajaran bahasa Indonesia di masa pandemi ini agar menjadi optimal dalam pembelajaran jarak jauh.

. Berdasarkan hasil peneliti mewawancari seorang Guru Bahasa Indonesia Kelas VII SMP ISLAM ASY_SYUHADA KOTA BOGOR bahwa pembelajaran menggunakan media google sites (1) mampu membawa siswa lebih efektif, (2) mampu memberikan siswa berpikir lebih berkembang, (3) memungkinkan belajar dimana saja dan kapan saja, (4) meningkatkan interaksi belajar antara pembelajar dengan pengajar , (5) siswa mampu lebih memahami pembelajaran atau materi yang diberikan guru, (6) mampu memberikan siswa lebih detail dalam mengerjakan tugas, dan (7) siswa lebih bersemangat dalam mengerjakan tugas karena sudah ada jadwal pengumpulan tugasnya.

Alasan peneliti mengambil analisis pembelajaran media google sites karena siswa kelas VII SMP ISLAM ASY_SYUHADA KOTA BOGOR lebih efektif pembelajaran menggunakan media pembelajaran google sites dalam kondisi pandemi seperti ini. Oleh karena itu, peneliti mencoba meneliti "Pemanfaatan Media Pembelajaran Google Sites Dalam Pembelajaran Bahasa Indonesia Jarak Jaub Siswa Vii Smp Islam Asy-Syubada Kota Bogor”. Dengan menggunakan metode pembelajaran google sites dalam kondisi pandemi tersebut akan memberikan proses pembelajaran yang efektif, menyenangkan dan tidak membosankan.

Penelitian ini menggunakan kualitatif yaitu peneliti mewawancarai seorang Guru Bahasa Indonesia kelas VII, mewawancarai siswa-siswa kelas VII hanya 5 orang dan siswa yang lain di minta untuk mengisi kuesioner. Metode yang digunakan peneliti ini untuk mengumpulkan data dalam penelitian ini yaitu: a) wawancara b) Kuesioner c) Buku referensi e) observasi dan f) Dokumentasi. Tujuan peneliti untuk memanfaatkan google sites dalam proses pembelajaran dan mengetahui kemampuan siswa dalam proses pembelajaran Bahasa Indonesia. Peneliti mengambil subjek yaitu siswa kelas VII SMP Islam Asy-Syuhada. Dan 
hasil penelitian tersebut bahwa siswa kelas VII dalam proses pembelajaran menggunakan media google sites mampu membawa siswa lebih efektif dalam pembelajaran jarak jauh.

\section{METODE PENELITIAN}

Penelitian ini dilakukan pada hari Selasa, 17 November 2020 di SMP Islam AsySyuhada Bogor. Menggunakan metode kualtitatif. yaitu peneliti mewawancari Guru kelas VII dan membagikan kuesioner kepada siswa kelas VII kemudian mereka mengisi kuesioner tersebut. Subjek penelitian adalah siswa kelas VII SMP Islam Asy- Syuhada. Teknik pengumpulan data dalam penelitian ini mengisi kuesioner untuk menanggapi bagaimana media pembelajaran google sites VII SMP Islam Asy- Syuhada dalam pembelajaran jarak jauh. Dan mewawancari guru kelas VII SMP Islam Asy- Syuhada. Dalam pengumpulan data untuk meneliti ini yaitu 1) Wawancara 2) Kuesioner 3) Observasi dan 4) Dokumentasi.

\section{HASIL DAN PEMBAHASAN}

Berdasarkan penelitian yang dilakukan di sekolah SMP Islam Asy- Syuhada yaitu siswa kelas VII dalam menggunakan media pembelajaran dalam google sites dalam pembelajaran bahasa Indonesia memiliki kompetensi pengemabangan dan menghasilkan pembelajaran yang efektif. Siswa melakukan kelas daring dalam pembelajaran Bahasa Indonesia dilakukan seminggu dua kali pertemuan. Dalam pembelajaran Bahasa Indonesia guru menjelaskan materi dengan menggugah materi pada google sites, siswa tidak perlu copy file menggunakan flasdisk sehingga siswa tidak perlu kerepotan untuk copy paste, siawa tinggal mengunduhnya saja.

\section{a) Hasil Kuesioner Siswa Kelas VII SMP Islam Asy- Syuhada Menggunakan Google Sites}

Proses pembelajaran Bahasa Indonesia yang dilakukan siswa kelas VII SMP Islam Asy- Syuhada menggunakan google sites tidak hanya memberikan keefektifan dalam pembelajaran jarak jauh . Tetapi memberikan siswa lebih aktif dan memberikan siswa berpikir lebih berkembang, memungkinkan belajar dimana saja dan kapan saja, meningkatkan interaksi belajar antara pembelajar dengan pengajar, siswa mampu lebih memahami pembelajaran atau materi yang diberikan guru, mampu memberikan siswa lebih detail dalam mengerjakan tugas, dan siswa lebih bersemangat dalam mengerjakan tugas karena sudah ada jadwal pengumpulan tugasnya.

Dibawah ini merupakan hasil kuesioner siswa VII SMP Islam Asy- Syuhada menggunakan google sites dalam pembelajaran Bahasa Indonesia.

\begin{tabular}{|l|l|c|c|}
\hline NO & \multicolumn{1}{|c|}{ PEMAHAMAN SISWA } & SETUJU & TIDAK SETUJU \\
\hline 1. & $\begin{array}{l}\text { Media google sites mampu } \\
\text { memberikan } \begin{array}{r}\text { keefektifan } \\
\text { pembelajaran Bahasa Indonesia } \\
\text { dalam jarak jauh. }\end{array}\end{array}$ & 28 Siswa & Siswa \\
\hline
\end{tabular}




\begin{tabular}{|c|c|c|c|}
\hline 2. & $\begin{array}{l}\text { Guru menjelaskan materi secara } \\
\text { detail mengenai pembelajaran } \\
\text { Bahasa Indonesia. }\end{array}$ & 30 Siswa & - \\
\hline 3. & $\begin{array}{l}\text { Media google sites memberikan } \\
\text { informasi tugas yang akan } \\
\text { dikerjakan siswa, sehingga siswa } \\
\text { mengetahui kapan tugas akan } \\
\text { dikumpulkan. }\end{array}$ & 25 Siswa & 5 Siswa \\
\hline 4. & $\begin{array}{l}\text { Media google sites dapat } \\
\text { menyimpan silabus pada materi } \\
\text { pembelajaran yang akan dilakukan } \\
\text { dari awal sampai akhir. }\end{array}$ & 23 Siswa & 7 Siswa \\
\hline 5. & $\begin{array}{l}\text { Dalam masa pandemi } \text { Covid-19 } \\
\text { media google sites sangat baik } \\
\text { untuk digunakan } \\
\text { pembelajaran Bahasa } \\
\text { jarak jauh. }\end{array}$ & 27 Siswa & 3 Siswa \\
\hline 6. & $\begin{array}{l}\text { Media google sites dapat diakses } \\
\text { secara gratis. }\end{array}$ & 30 Siswa & - \\
\hline 7. & $\begin{array}{l}\text { Media google sites dapat melihat } \\
\text { siswa untuk aktif dalam mengamati } \\
\text { video yang bisa langsung di search } \\
\text { di Youtube secara langsung, } \\
\text { sehingga siswa bisa mencari video } \\
\text { yang terkait pembelajaran Bahasa } \\
\text { Indonesia. }\end{array}$ & 26 Siswa & 4 Siswa \\
\hline 8. & $\begin{array}{l}\text { Media google dapat memberikan } \\
\text { pengumuman kepada siswa } \\
\text { mengenai link yang akan dibuka } \\
\text { oleh siswa. Misalnya, guru } \\
\text { membuat link untuk siswa, } \\
\text { kemudian siswa membuka link } \\
\text { tersebut untuk referensi tugas } \\
\text { mengenai materi. }\end{array}$ & 25 Siswa & 5 Siswa \\
\hline
\end{tabular}

Tabel 1. Hasil Kuosioner Siswa Kelas VII SMP Islam Asy-Syuhada

Bedasarkan hasil kuesioner di atas jumlah siswa 30 orang yaitu sebagai berikut:

1) Keefektifan dalam pembelajaran $=28$ siswa (setuju) dan 2 siswa (tidak setuju)

2) Guru menjelaskan materi = 30 siswa (setuju) dan 0 siswa (tidak setuju)

3) Informasi tugas = 25 siswa (setuju) dan 5 siswa (tidak setuju)

4) Menyimpan silabus = 23 siswa (setuju) dan 7 siswa (tidak setuju) 
5) Google sites diakses gratis

6) Dapat melihat Yotube

7) Pengumuman Tugas
$=30$ siswa (setuju) dan 0 siswa (tidak setuju)

= 26 siswa (setuju) dan 4 siswa (tidak setuju)

$=25$ siswa (setuju) dan 5 siswa (tidak setuju)

Hasil kuesioner pada siswa kelas VII SMP Islam Asy-Syuhada Kota Bogor menunjukan bahwa siswa lebih efektif menggunakan media google sites dalam pembelajaran Bahasa Indonesia. Karena dalam menggunakan media google sites mampu memberikan keefektifan pembelajaran Bahasa Indonesia dalam jarak jauh, Guru menjelaskan materi secara detail mengenai pembelajaran Bahasa Indonesia, media google sites memberikan informasi tugas yang akan dikerjakan siswa, sehingga siswa mengetahui kapan tugas akan dikumpulkan.

Media google sites dapat melihat siswa untuk aktif dalam mengamati video yang bisa langsung di search di Youtube secara langsung, sehingga siswa bisa mencari video yang terkait pembelajaran Bahasa Indonesia, dan media google dapat memberikan pengumuman kepada siswa mengenai link yang akan dibuka oleh siswa. Misalnya, guru membuat link untuk siswa, kemudian siswa membuka link tersebut untuk referensi tugas mengenai materi.

b) Keaktifan Siswa dalam Pembelajaran Menggunakan Media Google Sites Dalam Pembelajaran Bahasa Indonesia

\begin{tabular}{|l|l|c|}
\hline NO & Keaktifan Siswa & Nilai Skor \\
\hline 1. & $\begin{array}{l}\text { Siswa dapat mengakses halaman google site } \\
\text { dengan baik yang telah di share oleh guru } \\
\text { Bahasa Indonesia. }\end{array}$ & 80 \\
\hline 2. & $\begin{array}{l}\text { Siswa disiplin mengerjakan tugas karena sudah } \\
\text { ada pengumuman batas waktu yang telah } \\
\text { dibuat oleh guru. }\end{array}$ & 90 \\
\hline 3. & $\begin{array}{l}\text { Siswa mampu berpikir luas mengenai materi } \\
\text { bahasa Indonesia. }\end{array}$ & 92 \\
\hline 4. & $\begin{array}{l}\text { Siswa lebih memahami mata pelajaran Bahasa } \\
\text { Indonesia dengan baik, contohnya dalam } \\
\text { menyusun teks berita, siswa bisa melihat video } \\
\text { mengenai teks berita, dan bagaimana cara } \\
\text { menyusun teks berita maka siswa dapat } \\
\text { melihat video yang sudah di share guru. }\end{array}$ & 97 \\
\hline 5. & $\begin{array}{l}\text { Keaktifan siswa dalam membaca lebih efektif } \\
\text { karena siswa bisa membaca kembali mengenai } \\
\text { materi yang disampaikan guru dalam waktu } \\
\text { kapanpun. }\end{array}$ & \\
\hline
\end{tabular}

Tabel 2. Hasil Keaktifan Siswa dalam Pembelajaran Menggunakan Media Google Sites 
Hasil penelitian siswa kelas VII SMP Islam Asy-Syuhada dalam menggunakan google sites menunjukan keaktifan siswa dalam pembelajaran Bahasa Indonesia. Siswa dalam menggunakan google sites Siswa dapat mengakses halaman google site dengan baik yang telah di share oleh guru Bahasa Indonesia $80 \%$, Siswa disiplin mengerjakan tugas karena sudah ada pengumuman batas waktu yang telah dibuat oleh guru $90 \%$, Siswa mampu berpikir luas mengenai materi bahasa Indonesia 92\%, Siswa lebih memahami mata pelajaran Bahasa Indonesia dengan baik, contohnya dalam menyusun teks berita, siswa bisa melihat video mengenai teks berita, dan bagaimana cara menyusun teks berita maka siswa dapat melihat video yang sudah di share guru 97\%, keaktifan siswa dalam membaca lebih efektif karena siswa bisa membaca kembali mengenai materi yang disampaikan guru dalam waktu kapanpun. 95\%.

Google sites sangat bermanfaat bagi siswa kelas VII SMP Islam Asy-Syuhada dalam pembelajaran Bahasa Indonesia, karena google sites membawa perubahan siswa dalam pembelajaran Bahasa Indonesia dalam pembelajaran jarak jauh. Siswa tidak hanya efektif dalam pembelajaran nya tetapi, siswa juga tidak merasa bosan dalam pembelajaran menggunakan google sites. Google sites sangat baik untuk dijadikan pembelajaran di masa pandemi Covid-19.

c) Keaktifan Siswa Dalam Menulis Teks Berita Menggunakan Media Pembelajaran Google Sites

Berdasarkan hasil penelitian siswa kelas VII SMP Islam Asy-Syuhada. Siswa kelas VII merasa kesulitan dalam memahami teks berita. Sebelumnya kelas VII selama masa pandemi sebelumnya tidak menggunkan google sites hanya diskusi menggunakan Whatsapp. Siswa kelas VII sulit memahami dalam materi teks berita, kemudian guru mencoba untuk menggunakan kelas daring dengan menggunakan google sites hasilnya bahwa siswa lebih memahami materi yang disampaikan dengan menggunakan google sites.

Teks berita merupakan teks dalam bentuk informasi mengnai kejadian dalam bentuk tertulis maupun bentuk yang lain sehingga dapat memberikan informasi kepada pembaca.

Dalam pembelajaran teks berita guru mengajarkan siswa dengan menggunakan media pembelajaran google sites yaitu guru menjelaskan materi teks berita dengan secara detail, dan guru harus dapat mencotohkan bagaimana penulisan teks berita dalam bentuk video yang di share oleh guru, kemudian siswa diminta untuk melihat dan menanggapi video mengenai teks berita. Berikut ini hasil penelitian siswa dalam memahami teks berita menggunakan media pembelajaran google sites siswa kelas VII SMP Islam Asy-Syuhada. 


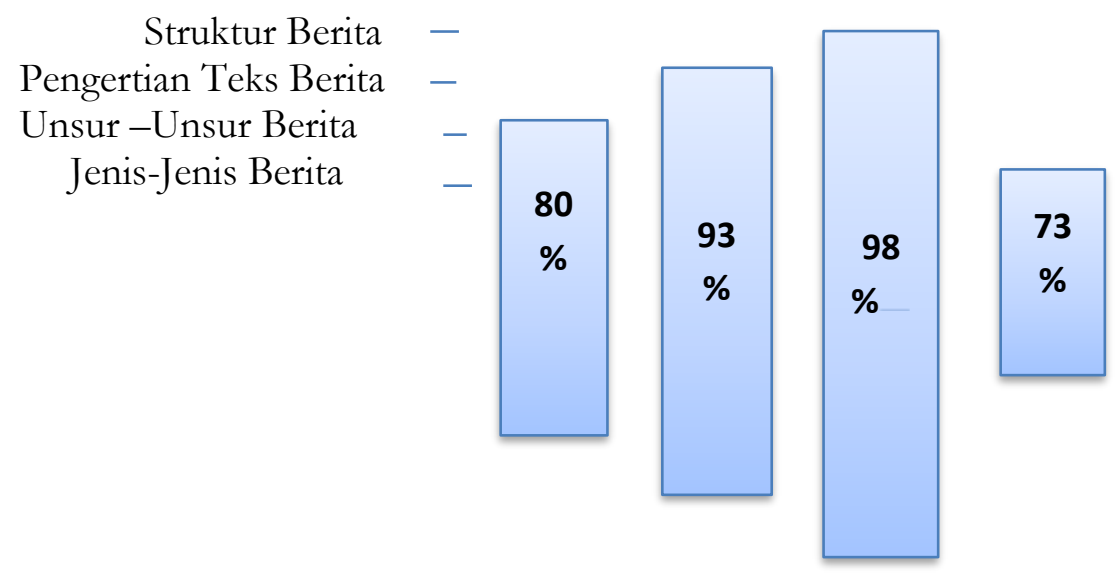

Gambar 1. Grafik memahami teks berita menggunakan media pembelajaran google sites siswa kelas VII SMP Islam Asy-Syuhada.

Bedasarkan hasil penelitian bahwa siswa dalam mempelajari teks berita menggunakan google sites menghasilkan perkembangan yang baik dan siswa mengasilkan nilai yang baik dari sebelumnya. Siswa aktif dalam menulis teks berita karena dengan menggunakan google sites siswa bisa mengakses langsung video mengenai teks berita di Youtube secara langsung dengan menggunkan google sites. Siswa memahami struktur berita mendapatkan nilai $98 \%$ metode yang digunakan dalam mempelajari siswa berlatih untuk menanggapi video yang diberikan oleh guru kemudian dianalisis. Siswa memahami pengertian teks berita mendapatkan nilai 93\% metode yang dilakukan siswa di perintahkan membaca materi yang diberikan oleh guru yang terdapat di google sites kemudian siswa ditugaskan untuk meringkas materi tersebut siswa diminta untuk mereview materi pengertian teks berita. Siswa memahami unsur-unsur berita mendaptkan nilai $80 \%$ siswa metode yang dilakukan siswa membaca materi yang disampaikan oleh guru . Dan siswa untuk memahami jenis-jenis berita mendapatkan nilai 73\% metode yang dilakukan siswa ditugaskan mencari secara langsung di google sites materi jenis-jenis berita kemudian dipresentasikan dengan membuat video kemudian di unggah secara langsung di aplikasi google sites.

Oleh karena itu siswa Kelas VII SMP Islam Asy-Syuhada dalam pembelajaran bahasa Indonesia jarak jauh menggunkan media google sites dapat mengembangkan kemampuan siswa dalam proses belajar Bahasa Indonesia. Siswa lebih memahami materi yang disampaikan dengan menggunkaan google sites. Karena itu googel sites dapat memberikan manfaat untuk siswa Kelas VII Islam Asy-Syuhada mampu memberikan siswa berpikir lebih berkembang, memungkinkan belajar dimana saja dan kapan saja, meningkatkan interaksi belajar antara pembelajar dengan pengajar ,siswa mampu lebih memahami pembelajaran atau materi yang diberikan guru, mampu memberikan siswa lebih detail dalam mengerjakan tugas, dan siswa lebih bersemangat dalam mengerjakan tugas karena sudah ada jadwal pengumpulan. 


\section{KESIMPULAN}

Berdasarkan hasil penelitian siwa Kelas VII SMP Islam Asy-Syuhada dalam pembelajaran bahasa indoenesia jarak jauh dalam masa pandemi Covid-19 ini menggunakan google sites. Google sites merupakan cara yang praktis dalam pembelajaran karena memberikan informasi pembelajaran dengan cepat dan bisa diakses dimana pun dan kapan pun. Google sites dapat memberikan efektif dalam proses pembelajaran jarak jauh dalam kondisii pandemi Covid-19, karena memberikan kemudahan dalam proses pembelajaran. Manfaat google sites yaitu sebagai berikut (1) google sites dapat membuat siswa lebih menarik dan menyenangkan (2) google sites dapat memberikan materi pembelajaran yang bisa diunduh sehingga siswa dapat belajar dari materi dimana pun dan kapan pun (3) goole sites dapat memberikan materi yang dari awal sampai akhir pertemuan, siswa dapat membaca kembali materi yang diberikan oleh guru karena materi tidak otomatis hilang (4) siswa dapat mengaploud tugas yang sudah diberikan tempat tugasnya tersendiri (5) google sites dapat memberikan pengumuman tersendiri mengenai tugas, atau informasi yang lain. Oleh karena itu pada artikel kali ini akan membahas mengenai bagaimana pemanfaatan google sites dalam pembelajaran bahasa Indonesia di masa pandemi ini agar menjadi optimal dalam pembelajaran jarak jauh.

Oleh karena itu siswa Kelas VII SMP Islam Asy-Syuhada dalam pembelajaran bahasa Indonesia jarak jauh menggunkan media google sites dapat membawa siswa lebih memahami materi yang disampaikan dengan menggunkaan google sites. Karena itu googel sites dapat memberikan manfaat untuk siswa Kelas VII Islam Asy-Syuhada mampu memberikan siswa berpikir lebih berkembang, memungkinkan belajar dimana saja dan kapan saja, meningkatkan interaksi belajar antara pembelajar dengan pengajar, siswa mampu lebih memahami pembelajaran atau materi yang diberikan guru, mampu memberikan siswa lebih detail dalam mengerjakan tugas, dan siswa lebih bersemangat dalam mengerjakan tugas karena sudah ada jadwal pengumpulan.xdf

\section{DAFTAR PUSTAKA}

Bambang Warsita. (2008). Teknologi Pembelajaran, Landasan dan Aplikasinya . Jakarta: PT. Rineka Cipta.

Hamzah, Nina Lamatenggo. (2011). Teknologi Komunikasi \& Informasi Pembelajaran. Jakarta: PT. Bumi Aksara.

Mahnun. Nunu. (2012). Media Pembelajaran (Kajign terhadap Langkah-Langkah Pemiliban Media dan Implementasinya dalam Pembelajaran). Dalam Jurnal Pemikiran Islam : Vol. 37, No 1:27.

Rusman, Deni Kurniawan dan Cepi Riyana. (2013). Pembelajaran Berbasis Teknologi Informasi dan Komunikasi. Jakarta: RajaGrafindo Persada.

Rubhan Masykur, Nofrizal, Muhamad Syazali. (2017). Pengembangan Media Pembelajaran Matematika dengan Macromedia Flash. Jurnal Pendidikan Matematika, Vol. 8, No. 2, Hal. 179.

Winataputra, U. S., Delfi, R., Pannen, P., \& Mustafa, D. (2014). Hakikat Belajar dan Pembelajaran. Hakikat Belajar dan Pembelajaran, 1-46. 
